\title{
ÚNG DỤNG DŨ̉ LIỆ ẢNH VỆ TINH VNREDSAT-1A XÁC ĐỊNH HÀM LƯợNG ĐỘ ĐỤC TRONG NƯỚC MẶT MộT SỐ HỔ KHU VỰC HÀ NỘI
}

\section{ĐINH TH! THU HIỀN}

Trường Đại học Điện lục

\section{Tóm tắt}

Hàm lương độ đục là một trong nhũng thông số quan trọng khi đánh giá chất lượng nước mặt. Các nghiên cưu trên thế giới cho thấy, hàm lượng độ đục có mối quan hệ chặt chẽ với phổ phản xạ xác định tù ảnh vệ tinh quang học. Bài báo này trình bày kết quả sủ dụng ảnh vệ tinh quang học VNREDSat-1A nhằm xác định hàm lượng độ đục trong nước mặt một số hồ ở khu vực Hà Nội. Kết quả nhận được trong nghiên cúu có thể sư dụng phục vu xây dụng bản đồ phân bố hàm lượng độ đục, đánh giá và giám sát chất lượng nước mặt.

\section{1. Đặt vấn đề}

Trong hơn 3 thập kỷ qua, công nghệ viễn thám đã có những thành tựu hết sức to lớn trong lĩnh vực nghiên cứu Trái đất và trở thành một công cụ quan trọng phục vụ nghiên cứu, giám sát môi trường nói chung, môi trường nước mặt nói riêng. Nhiều nghiên cứu trên thế giới đã chứng minh phổ phản xạ xác định từ ảnh vệ tinh quang học có quan hệ chặt chẽ với hàm lượng các thông số chất lượng nước như độ đục (turbidity), chất lơ lửng (suspended sediment), chất diệp lục (chlorophyll), chất hữu cơ hòa tan...[5]. Ở Việt Nam cũng đã có một số nghiên cứu sử dụng tư liệu ảnh vệ tinh quang học để đánh giá chất lượng nước khu vực Hồ Tây (Hà Nội) [4], hồ Trị An [6].

VNREDSat-1A là vệ tinh quang học quan sát Trái Đất đầu tiên của Việt Nam, có khả năng chụp ảnh toàn bộ các khu vực trên bề mặt Trái Đất. VNREDSat-1A được phóng thành công lên quỹ đạo vào 07/05/2013, được trang bị bộ cảm biến quang học bao gồm 5 kênh phổ, trong đó có 4 kênh đa phổ với độ phân giải không gian $10 \mathrm{~m}$ và 01 kênh toàn sắc với độ phân giải không gian 2,5m (bảng 1). Mặc dù vậy, cho đến nay hầu như chưa có nghiên cứu nào trong ứng dụng ảnh vệ tinh VNREDSat-1A phục vụ đánh giá chất lượng nước. Bài báo này trình bày kết quả nghiên cứu sử dụng ảnh vệ tinh VNREDSat-1A xác định hàm lượng thông số độ đục trong nước mặt các hồ, đầm ở khu vực Hà Nội.

\section{Dữ liệu và phương pháp nghiên cứu}

\subsection{Dũ liệu}

a) Dũ liệu viễn thám

Dữ liệu viễn thám sử dụng trong nghiên cứu là ảnh vệ tinh quang học độ phân giải cao VNREDSat-1A, chụp ngày 21/12/2017 khu vực Hà Nội. (Xem hình 1)

\section{b) Số liệu quan trắc}

Để đánh giá mối quan hệ giữa phổ phản xạ xác định từ ảnh viễn thám và hàm lượng độ đục,

Bảng 1: Đặc điểm các kênh phổ ảnh vệ tinh VNREDSat-1A

\begin{tabular}{|c|c|c|c|}
\hline STT & Kênh ảnh & Bước sóng $(\boldsymbol{\mu m})$ & Độ phân giải không gian $(\mathbf{m})$ \\
\hline 1 & B1 (xanh lam) & $0,45-0,52$ & 10 \\
\hline 2 & B2 (xanh lục) & $0,53-0,60$ & 10 \\
\hline 3 & B3 (đỏ) & $0,62-0,69$ & 10 \\
\hline 4 & B4 (cận hồng ngoại) & $0,76-0,89$ & 10 \\
\hline 5 & PAN (toàn sắc) & $0,45-0,75$ & 2,5 \\
\hline
\end{tabular}

Ngày nhận bài: 15/8/2018, ngày chuyển phản biện: 17/8/2018, ngày chấp nhận phản biện: 06/9/2018, ngày chấp nhận đăng: 10/9/2018 
trong nghiên cứu sử dụng 16 mẫu chất lượng nước. Các mẫu nước mặt được phân bố đều trên khu vực nghiên cứu nhằm đảm bảo thể hiện đặc trưng phân bố hàm lượng các chất ô nhiễm nước mặt. Quá trình lấy mẫu, bảo quản và phân tích được thực hiện theo quy định trong Quy chuẩn quốc gia về chất lượng nước mặt QCVN 08MT:2015/BTNMT [1]. Tọa độ các điểm lấy mẫu được thể hiện trong bảng 2 .

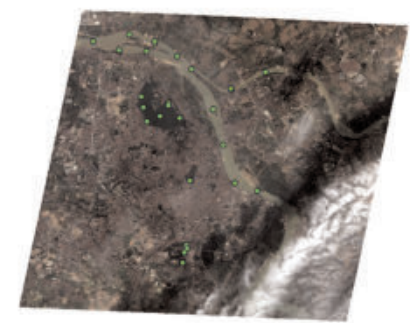

Hìn 1: Anh vệ tinh quang hoc VNREDSat-1A khu vục Hà Nọi ngày 21/12/2017 và vị trí các điểm lấy mẫu chất lương nước

c) Số liệu đo phổ hiện truò̀ng

Máy đo quang phổ cầm tay GER 1500 được sử dụng để xác định phổ phản xạ hiện trường nhằm tính toán độ lệch phổ trung bình với phổ phản xạ xác định từ ảnh vệ tinh VNREDSat-1A theo công thức:

$$
\Delta \rho(\lambda)=\frac{\sum_{i=1}^{n}\left(\rho(\lambda)-\rho_{w}(\lambda)\right)}{n}
$$

Trong đó: $\mathrm{n}$ là số điểm đo phổ hiện trường,

$\rho(\lambda)$ - phổ phản xạ hiện trường,

$\rho_{\mathrm{W}}(\lambda)$ - phổ phản xạ xác định từ ảnh vệ tinh.

Chênh lệch giữa phổ phản xạ hiện trường và phổ phản xạ xác định từ ảnh vệ tinh VNREDSat$1 \mathrm{~A}$ được thể hiện trong bảng 3 .

Phân tích kết quả đạt được cho thấy, độ chênh lệch giữa phổ phản xạ hiện trường và phổ phản xạ xác định từ ảnh vệ tinh VNREDSat-1A ở các kênh xanh lam, xanh lục, đỏ và cận hồng ngoại đạt lần lượt là 0,$0142 ; 0,0189 ; 0,0183$ và 0,0099 . Độ lệch phổ này được sử dụng nhằm hiệu chỉnh khí quyển ảnh vệ tinh VNREDSat-1A.

\subsection{Phương pháp nghiên cứu}

Để đánh giá mối quan hệ giữa phổ phản xạ mặt nước và hàm lượng độ đục, trong nghiên cứu sử dụng giá trị phản xạ phổ cả ở 4 kênh đa phổ ảnh vệ tinh VNREDSat-1A, bao gồm kênh 1 (xanh lam), kênh 2 (xanh lục), kênh 3 (đỏ) và kênh 4 (cận hồng ngoại). Phương pháp hồi quy bội tuyến tính được sử dụng để xây dựng hàm

Bảng 2: Tọa độ các điểm lấy mẫu chất lượng nước

\begin{tabular}{|c|c|c|c|}
\hline \multirow{2}{*}{ STT } & \multirow{2}{*}{ Tên điểm quan trắc } & $\mathbf{X}$ & Tọa độ $(\mathbf{m})$ \\
\cline { 3 - 4 } & & 587142 & $\mathbf{Y}$ \\
\hline 1 & Hồ Linh Đàm 1 & 587159 & 2319033 \\
\hline 2 & Hồ Linh Đàm 2 & 586982 & 2318789 \\
\hline 3 & Hồ Linh Đàm 3 & 586928 & 2318503 \\
\hline 4 & Hồ Zin-1 & 586939 & 2317839 \\
\hline 5 & Hồ Zin-2 & 586825 & 2317837 \\
\hline 6 & Hồ Zin-3 & 586855 & 2317834 \\
\hline 7 & Hồ Zin-4 & 586886 & 2317846 \\
\hline 8 & Hồ Tứ Kỳ & 585965 & 2317779 \\
\hline 9 & Hồ Tây 1 & 584518 & 2329010 \\
\hline 10 & Hồ Tây 2 & 584294 & 2327719 \\
\hline 11 & Hồ Tây 3 & 585369 & 2328697 \\
\hline 12 & Hồ Tây 4 & 586669 & 2328081 \\
\hline 13 & Hồ Tây 5 & 585930 & 2327969 \\
\hline 14 & Hồ Tây 6 & 584141 & 2328835 \\
\hline 15 & Hồ Tây 7 & 587355 & 2329457 \\
\hline 16 & Hồ công viên Thống Nhất & & 2323561 \\
\hline
\end{tabular}


Nghiên cúu - Úng dụng

Bảng 3: Chênh lệch giũa phổ phản xạ hiện trường và phổ phản xạ xác định tù ảnh vệ tinh VNREDSat-1A

\begin{tabular}{|c|c|c|c|c|c|c|c|c|}
\hline \multirow{2}{*}{ Điểm } & \multicolumn{4}{|c|}{ Phản xạ vệ tinh } & \multicolumn{4}{c|}{ Phản xạ hiện trường } \\
\cline { 2 - 9 } & Blue band & $\begin{array}{c}\text { Green } \\
\text { band }\end{array}$ & Red band & NIR band & Blue band & $\begin{array}{c}\text { Green } \\
\text { band }\end{array}$ & Red band & NIR band \\
\hline Hồ Tây 1 & 0,109 & 0,096 & 0,073 & 0,066 & 0,083 & 0,071 & 0,056 & 0,049 \\
\hline Hồ Tây 2 & 0,111 & 0,099 & 0,078 & 0,066 & 0,095 & 0,077 & 0,062 & 0,055 \\
\hline Hồ Tây 3 & 0,11 & 0,098 & 0,073 & 0,063 & 0,096 & 0,081 & 0,07 & 0,056 \\
\hline Hồ Tây 4 & 0,107 & 0,093 & 0,07 & 0,059 & 0,088 & 0,073 & 0,054 & 0,047 \\
\hline Hồ Tây 5 & 0,11 & 0,095 & 0,073 & 0,064 & 0,085 & 0,071 & 0,055 & 0,046 \\
\hline Hồ Tây 6 & 0,11 & 0,098 & 0,075 & 0,068 & 0,091 & 0,075 & 0,059 & 0,048 \\
\hline Hồ Tây 7 & 0,109 & 0,098 & 0,073 & 0,063 & 0,093 & 0,077 & 0,06 & 0,051 \\
\hline Hồ CV Thống Nhất & 0,107 & 0,093 & 0,07 & 0,059 & 0,09 & 0,083 & 0,063 & 0,052 \\
\hline Tồng & 0,763 & 0,77 & 0,0585 & 0,508 & 0,721 & 0,608 & 0,479 & 0,404 \\
\hline$\Delta \boldsymbol{\Delta}$ & $\mathbf{0 , 0 1 4 2}$ & $\mathbf{0 , 0 1 8 9}$ & $\mathbf{0 , 0 1 8 3}$ & $\mathbf{0 , 0 0 9 9}$ & & & & \\
\hline
\end{tabular}

hồi quy. Cuối cùng, hàm lượng độ đục trong nước mặt các hồ thuộc khu vực Hà Nội có thể được xác định theo công thức sau:

Turbidity(NTU) $=-39,758 B_{1}-544,859 B_{2}+$ $129,239 B_{3}+660,904 B_{4}+19,07$

Trong đó: $\mathrm{B}_{1}, \mathrm{~B}_{2}, \mathrm{~B}_{3}, \mathrm{~B}_{4}$ là phổ phản xạ mặt nước xác định từ các kênh đa phổ ảnh vệ tinh VNREDSat-1A. Giá trị hệ số $\mathrm{R}^{2}$ trong hàm hồi quy trên đạt 0,774 , thể hiện mối quan hệ chặt chẽ giữa phản xạ mặt nước và hàm lượng độ đục.

\section{Kết quả và thảo luận}

Sử dụng công thức (2), trong nghiên cứu tiến hành tính toán hàm lượng độ đục cho nước mặt các hồ tại khu vực Hà Nội, sau đó khu vực các hồ, đầm được tách riêng để xây dựng bản đồ phân bố hàm lượng độ đục (hình 2). Phân tích kết quả đạt được cho thấy, hàm lượng độ đục trong nước mặt khu vực hồ, ao ở Hà Nội ngày 21/12/2017 nhìn chung có sự chênh lệch không lớn. Giá trị độ đục thẩp nhất và cao nhất trong nước mặt các hồ, đầm ở Hà Nội xác định từ ảnh vệ tinh VNREDSat-1A ngày 21/12/2017 đạt $4,834(\mathrm{NTU})$ và 61.806 (NTU), trong đó phần lớn nước mặt ở các hồ, đầm khu vực Hà Nội có hàm lượng độ đục trong khoảng từ 30 - 60 NTU. Giá trị hàm lượng độ đục đạt thấp ghi nhận cục bộ tại Đầm Đỗi, gần hồ Định Công. Trong khi đó tại các hồ, đầm lớn như Hồ Tây, hồ Định Công, hồ Linh Đàm, các hồ trong công viên Yên Sở, Đầm Lớn, giá trị hàm lượng độ đục nhìn chung khá tương đồng nhau và thấp hơn đáng kể so với đợt quan trắc tháng 10/2016 [2, 3].

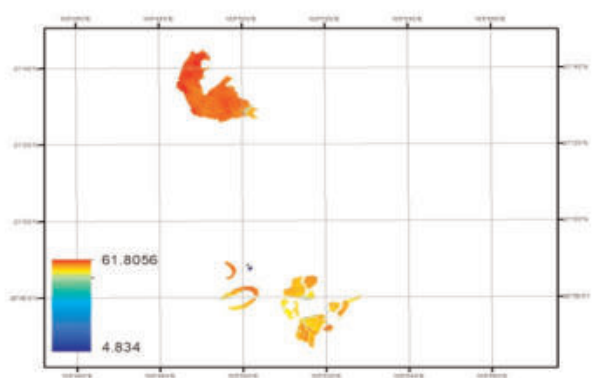

Hình 2: Kêt quả đánh giá phân bố hàm lượng độ đục trong nước mặt một số hồ khu vưc Hà Nội tù̀ ảnh vẹ tinh VNREDSat-1A ngày 21/12/2017

\section{Kết luận}

Ảnh vệ tinh quang học VNREDSat-1A có thể sử dụng hiệu quả trong xác định hàm lượng độ đục trong nước mặt. Kết quả nhận được cho thấy, phản xạ phổ tại các kênh đa phổ ảnh vệ tinh VNREDSat-1A có mối quan hệ chặt chẽ với hàm lượng độ đục, thể hiện ở giá trị hệ số $\mathrm{R}^{2}$ đạt khá cao $(0,774)$.

Phân tích kết quả đạt được cho thấy, các hồ, đầm ở khu vực Hà Nội nhìn chung có hàm lượng độ đục không cao và không có sự chênh lệch lớn. Phần lớn nước mặt trong các hồ, đầm ở Hà Nội có độ đục nằm trong khoảng từ 30 đến 60 NTU. Hàm lượng độ đục đạt thấp được ghi nhận ở một số hồ, đầm như Đầm Đỗi.

Kết quả nhận được trong nghiên cứu giúp cung cấp thông tin kịp thời cho các nhà quản lý, phục vụ công tác theo dõi, giám sát, đánh giá và bảo vệ nguồn tài nguyên nước mặt. $\bigcirc$ 


\title{
Tài liệu tham khảo
}

[1]. Bộ Tài nguyên và Môi trường (2015). Quy chuẩn kỹ thuật quốc gia về chất lượng môi trường nước mặt (QCVN 08MT:2015/BTNMT).

[2]. Đinh Thị Thu Hiền, Trần Xuân Trường, Nguyễn Văn Trung (2017), "Nghiên cứu phương pháp xác định các thông số chât lượng nước mặt từ tư liệu ảnh vệ tinh quang học VNREDSat $1 \mathrm{~A}$ ", Tạp chí Tài nguyên và Môi trường, số 24 (278), kỳ 2, tháng 12 năm 2017

[3]. Đinh Thị Thu Hiền, Lê Thanh Toàn (2018), "Mối quan hệ giữa phổ phản xạ và hàm lượng độ đục (NTU) nước mặt khu vực hồ, đầm hà nội từ dữ liệu ảnh vệ tinh vnredsat-1a ngày 20/10/2016 sau khi hiệu chỉnh khí quyển", Tạp chí Tài nguyên và Môi trường, số 24 (278), kỳ 1, tháng 7 năm 2018.

\section{Summary}

\section{Using VNREDSat-1A multispectral data to calculate turbidity concentration in surface water of lakes in Hanoi area}

Dinh Thi Thu Hien

Electric Power University

Turbidity concentration is one of the important parameters for evaluating surface water quality. Previous published studies in the world have shown that the value of the turbidity is closely related to the reflectance, which calculated from optical satellite images. This paper presents the results of the use of VNREDSat-1A multispectral images to determine the turbidity concentrations in surface water of lakes in Hanoi area. The results obtained in the study can be used to create the distribution map of turbidity concentrations and to assess and monitor surface water quality. $\bigcirc$

\section{TÍNH SỐ HIỆU CHİNH DO ẢNH HƯởNG.....}

\author{
(Tiếp theo trang 37)
}

[10]. Torben Schüler (2000), On GroundBased GPS Tropospheric Delay Estimation; pp.

\section{Summary}

\section{Calculating the dry tropospheric correction for altimetry data in the East Sea}

Nguyen Van Sang, University of Mining and Geology

Pham Le Phuong, Nguyen Thanh Thuy, Vietnam Institute of Geodesy and Cartography

The purpose of the article is calculating the dry tropospheric corrections for altimetry data in the East Sea. The Saastamoinen formula is applied to calculate. The experimental calculations are made for the Cryosat-2 satellite data, Cycle 55th based on the two meteorological models NCEP and ECMWF. The calculated corrections and the averaged corrections are compared to those of the European Space Agency (ESA). The results of comparison show that, the averaged corrections of two meteorological models match those provided by the ESA. The accuracy of the averaged corrections of two meteorological models is improved. 0 